https://doi.org/10.22201/cimsur.18704115e.2021.v16.534 Revista Pueblos y fronteras digital • ARTíCULO DE INVESTIGACIÓN

\title{
La producción de sal en el sitio Gallo encantado (GE1), Chiapas, México: análisis de la tecnología cerámica desde la arqueología evolutiva

\author{
Salt production in Gallo encantado (GE1), Chiapas state, Mexico:
} an analysis of ceramic technology from a perspective of evolutionary Archeology
}

\author{
Marx Navarro Castillo \\ https://orcid.org/0000-0003-3472-152X \\ Universidad de Tlaxcala, México \\ marxnavc@yahoo.com \\ Brenda Guadalupe Jiménez Vázquez \\ (iD) https://orcid.org/0000-0002-0670-1807 \\ Centro de Investigaciones y Estudios Superiores en Antropología Social, México \\ Gpe_JimVaz132@hotmail.com \\ Hector Neff \\ https://orcid.org/0000-0002-2792-716X \\ Universidad Estatal de California, Long Beach \\ hector.neff@csulb.edu
}

\section{Resumen:}

La investigación se enfoca en la producción de sal de los periodos Preclásico y Posclásico Tardío, en el sitio Gallo encantado (GE1). Al usar la teoría de la evolución cerámica se modeló una propuesta que toma en cuenta los atributos estilísticos y funcionales de la cerámica para determinar las diferencias entre los dos periodos. Los resultados de la comparación directa de frecuencias indican que los atributos de estas cerámicas estuvieron presentes en ambos periodos y habrían contribuido a mejorar el proceso de producción de sal. Estas mejoras funcionales permiten interpretar que la especialización estuvo presente tanto en el Preclásico como en el Posclásico Tardío. A partir de ello, se infiere que la mayor demanda observada durante el Preclásico y la intensificación del comercio en el periodo Posclásico Tardío fueron las fuerzas impulsoras de esta especialización cerámica.

Palabras clave: producción salina, conjuntos cerámicos, selección natural, atributos estilísticos, atributos funcionales

Abstract:

This piece of research focuses on salt production during the Preclassic and late Postclassic periods in Gallo encantado (GE1). Using the theory of the evolution of ceramic traditions, a proposal was developed taking into account the stylistic and functional attributes portrayed by ceramics in order to define the differences between these two periods. The findings emerging from a direct comparison of frequency indicate that the attributes displayed by these ceramics characterize both periods and may have contributed to improve the salt production process. These functional improvements make it possible to understand the presence of that form of specialization in both the Preclassic and the Late Postclassic periods. Based on this interpretation, it can be inferred that the higher demand observed during the Preclassic period and the intensification of trade during the Late Postclassic period were the driving forces behind this specialization in ceramics.

Key words: Salt production, ceramic assemblages, natural selection, stylistic attributes, functional attributes 


\section{Introducción}

$\mathrm{D}$ esde tiempos remotos la sal ha sido un complemento indispensable en la dieta los seres humanos, ya que aporta los iones necesarios para que el organismo pueda desempeñar diversas funciones (Monckeberg, 2012). En la época prehispánica, además de ser un suplemento alimenticio, fue empleada como conservador de alimentos, mordente para el teñido de textiles, bien intercambiable y símbolo de prestigio, sin mencionar su uso ritual y medicinal (Liot, 1995; Murata, 2011; Parsons, 2015).

Pese a la importancia de este producto, son escasas las investigaciones que abordan temas relacionados con su producción. Esto se debe principalmente a que los restos de dicha actividad son muy limitados, por lo cual suelen pasar inadvertidos o ser confundidos con vestigios de otras actividades (Liot, 1995; Parsons, 2015). No obstante, algunos investigadores documentaron la presencia de salinas prehispánicas en el valle de Tehuacán (Sisson, 1973; Neely, Caran y Ramírez, 1997; Castellón, 2017), en el área maya (Woodfill, Dillion, Wolf, Avendaño y Canter, 2015; Andrews, 1991; McKillop, 1995, 2005; Murata, 2011), en la costa del Pacífico (Nance, 1992; 1994), en el golfo de México (Santley, 2004), en el occidente de México (Liot, 1995; Williams, 2016; 2020) y la cuenca de México (Parsons, 2015)

En años recientes, el Proyecto Arqueológico Costa del Soconusco (PACS) (Neff, 2012; 2014; Navarro y Neff, 2020) ha efectuado investigaciones en la zona de esteros y manglares de dicha región. Estas investigaciones permiten identificar una serie de marcadores culturales de producción de salina y cerámica en los montículos de la zona, entre los cuales destacan: instalaciones piro-tecnológicas (interpretadas como hornos o fogones), restos de carbón y ceniza solidificada, arcilla quemada, cilindros sólidos de tamaños variados (frecuentemente encontrados en posición vertical), cerámica burda similar en morfología y temporalidad al tipo Porvenir Tosca reportado por Nance (1992, 1994), en la salina del montículo Guzmán, en la costa de Guatemala.

Además de estos datos, el análisis de sedimentos por FTIR y XRF indica que el suelo de los montículos se expuso a temperaturas superiores a los $500^{\circ} \mathrm{C}$, las cuales, de acuerdo con Berna et al. (2007), son más altas que aquellas producidas por actividades domésticas. Esta exposición a altas temperaturas también se observó en la coloración rojiza-café de los sedimentos que constituyen los montículos estudiados. 
Por otro lado, los marcadores culturales demuestran que la zona de esteros y manglares del Soconusco oriental fue un área de intensa actividad salinera y cerámica. Alcanzó su mayor auge durante el Formativo Tardío y continuó desarrollándose hasta épocas recientes. Así lo señala Andrews (1980) y describe el proceso de elaboración de sal empleado en la Costa de Chiapas durante el siglo pasado. El proceso consistía en la filtración de sedimentos en grandes canoas para la obtención de salmuera, la cual era hervida en grandes vasijas, que posteriormente fueron remplazadas por peroles de hierro.

Con base en estas evidencias, el presente trabajo tiene como principal objetivo realizar una propuesta de análisis de los cambios y continuidades en los conjuntos cerámicos utilizados en la producción de sal durante dos periodos discontinuos en el sitio Gallo encantado (GE1), ubicado en la parte oriental del Soconusco, en el estado de Chiapas (véase Figura 1). Para ello se parte de una perspectiva neodarwiniana y de los planteamientos de la teoría de la evolución cerámica que nos permite ver los procesos de adaptación por parte de los habitantes y cómo estos se ven reflejados en la cultura material. Esta investigación cobra relevancia a partir de la ausencia de estudios sobre la cerámica salinera en la zona que permitan conocer y comprender el desarrollo de esta actividad.

\section{Área de estudio}

GE1 es uno de los más de 200 montículos identificados por PACS. El sitio consiste en un montículo ovalado, cuyo eje mayor presenta una orientación suroeste-noreste y mide $72 \mathrm{~m}$. Su eje menor, sureste-noroeste, mide $51 \mathrm{~m}$. Su altura es de $10.2 \mathrm{~m}$ sobre el nivel del mar y $5.3 \mathrm{~m}$ sobre el terreno circundante. GE1 forma parte del Complejo Gallo encantado; se localiza a 350 m de la playa y aproximadamente a $3.3 \mathrm{~km}$ al sureste de la boca del río Cahuacán, en el interior del manglar (véanse Figuras 1, 2, 3). Entre el sitio y la playa se encuentra un canal navegable por canoa, el cual forma parte de una amplia red que comunica diversas áreas del manglar (Neff, 2012; Romero, 2012). Dada su privilegiada ubicación, desde GE1 es posible tener acceso a los recursos necesarios para la producción de sal, como son el agua salada, combustible y arcillas. Los primeros trabajos de investigación, efectuados por PACS en GE1, determinaron que el núcleo del montículo se formó gradualmente por la acumulación de sedimentos lixiviados. Esto es consecuencia de la actividad salinera, tal como ocurre en otros montículos de la zona, entre ellos PIN7, CONO18, RS3, RS23 y BER19. 
Figura 1. Ubicación del montículo GE1

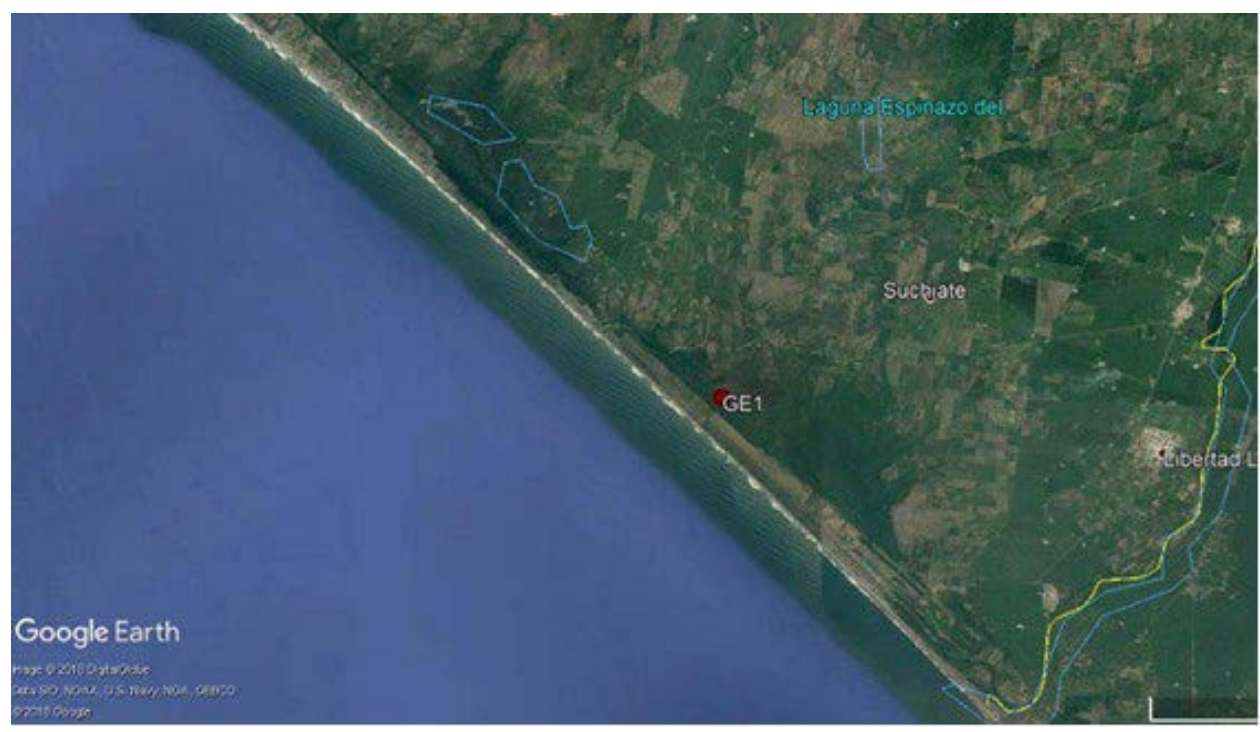

Fuente: Google Earth.

Figura 2. Imagen LIDAR de GE1

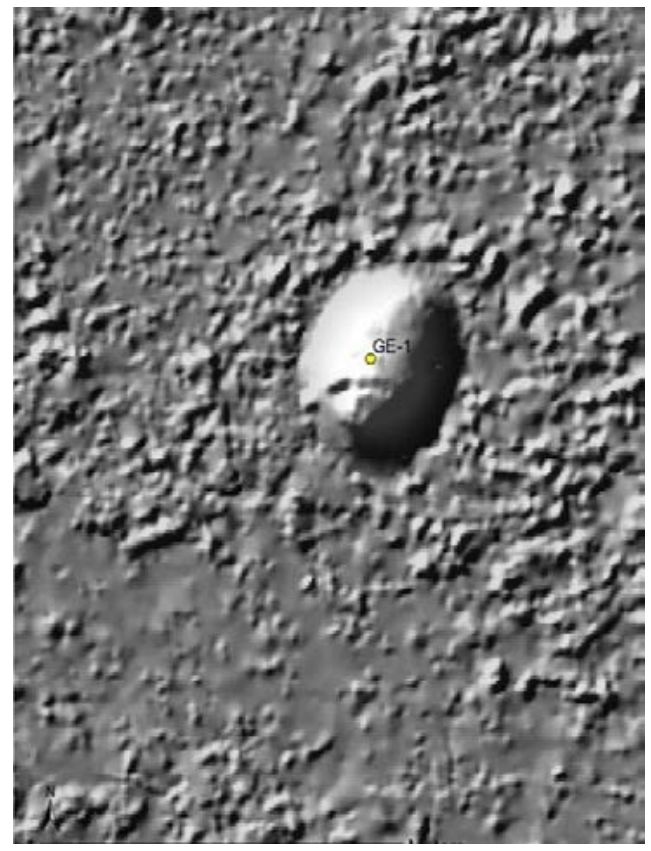

Figura 3. Mapa del sitio

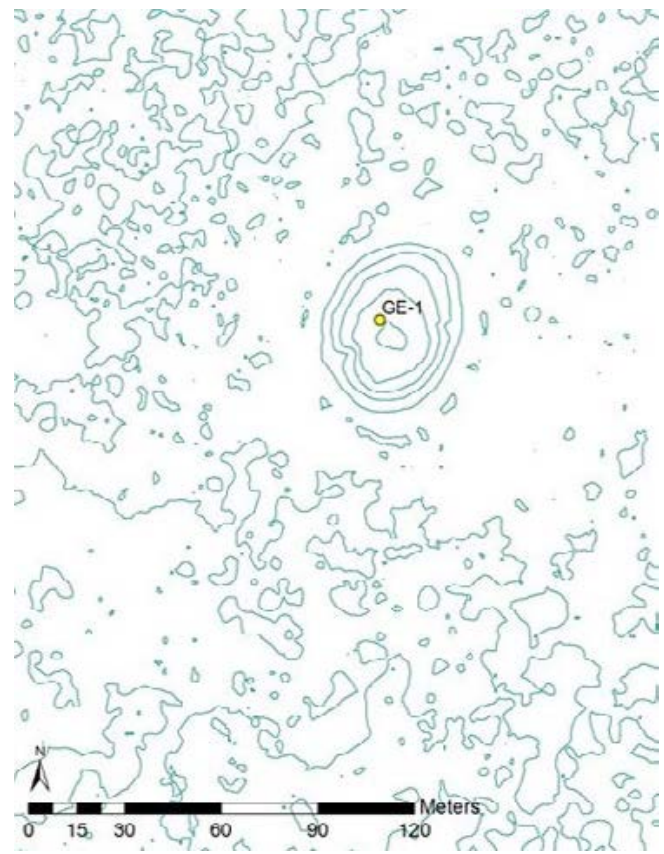

Fuente: elaboradas por Hector Neff.

Las excavaciones, realizadas en el sitio durante 2019, permitieron la identificación de un depósito del Complejo Bermúdez, el cual fue datado hacia el Formativo Tardío, y debajo de este se encontraron pequeñas cantidades de material del 
Formativo Temprano. En los niveles superiores se hallaron tiestos de Plomizo Tohil, diagnósticos del Posclásico Temprano y cerámica Gallo encantado con impresión textil, perteneciente al Posclásico Tardío. Esta ocupación fue corroborada por una muestra de carbón, que produjo una fecha de C14 que se extiende de 1404 a 1435 d.C., con un nivel de confianza de 95.4 por ciento.

Al igual que la mayoría de sitios investigados por PACS, la principal ocupación de GE1 se dio durante el Formativo Tardío, momento en el cual la zona litoral del oriente del Soconusco se dedicaba a la producción de sal destinada al consumo de las poblaciones agrícolas de la planicie costera y el piedemonte (Neff, Burger, Culleton, Kenneth y Jones, 2018). Durante este periodo, Izapa, ubicado a 40 km de GE1, también alcanzó su mayor ocupación y desarrollo artístico y se convirtió en uno de los centros más importantes de la costa del Soconusco (Rosenswig, 2019).

A diferencia del Formativo, durante el Posclásico Tardío el Soconusco se encontraba organizado en entidades políticas independientes, entre las que destacan: Xoconochco, Huixtla, Acapetahua, Mapastepec, Mazatán y Coyoacán. Las entidades mantenían una activa participación en las redes de comercio e intercambio a larga distancia (Voorhies y Gasco, 2004).

\section{Arqueología evolutiva y la teoría de la evolución cerámica}

Los avances registrados en los años setenta en las ciencias biológicas, principalmente los relacionados con el reconocimiento de la conducta como parte del fenotipo humano, impulsaron la aplicación de los planteamientos de la teoría de la evolución de Charles Darwin (1877) en diversos campos de estudio, incluyendo la arqueología (Dunnell, 1996a; Barton y Clark, 1997). El creciente interés en este enfoque evolutivo se hizo evidente con la publicación de artículos que señalaban la necesidad de explicar la evolución cultural a partir de una posición teórica con bases científicas (Dunell, 1982; Preucel, 1999). Estas aportaciones consolidaron los cimientos para el desarrollo de una nueva corriente teórica: la arqueología evolutiva, que plantea la aplicación de conceptos y procesos básicos de la teoría de la evolución y la biología evolutiva al estudio del cambio cultural en las sociedades del pasado (Dunnell, 1982, 1996a). La corriente está constituida por cuatro líneas de investigación: 1) Coevolución, 2) Ecología del comportamiento, 3) Evolución cognitiva y 4) Seleccionismo. La última explica el cambio en el registro arqueológico a través del mecanismo de selección natural. Su principal

exponente es Robert C. Dunnell (Dunnell, 1996a; Preucel, 1999; Lanata, Cardillo, Pineau y Rosenfeld, 2004). 
De acuerdo con Dunnell $(1982,1996$ ) los artefactos constituyen la expresión material de la conducta y, por lo tanto, forman parte del fenotipo humano. La variabilidad observada en los artefactos es producto del comportamiento de los seres humanos. El mecanismo de selección natural opera sobre esta variabilidad, determinando qué rasgos serán transmitidos culturalmente. Desde la perspectiva evolutiva neodarwiniana, el cambio se considera un proceso selectivo y se explica como una alteración en la frecuencia de las variables (Dunnell, 1996b; O’Brien, Holland, Hoard y Fox, 1994; Rindos, 1996). En este sentido, el cambio no es un sinónimo de progreso, sino de transformación.

Dunnell (1978, 1996a, 1996b), O'Brien y Holland (1996) y Broughton y O'Connell (1999) plantean que los artefactos poseen dos tipos de atributos: estilísticos y funcionales. El primero se caracteriza por ser adaptativamente neutral; es decir, que su presencia o ausencia está determinada por mecanismos distintos al de la selección natural (Dunnell, 1978). Es preciso señalar que tanto la biología moderna como la arqueología evolutiva admiten la existencia de procesos de transmisión aleatorios (Dunnell, 1996a; Boone y Smith, 1998).

A partir de los planteamientos generales de la arqueología evolutiva, Hector Neff $(1992,2001)$ desarrolló la teoría de la evolución cerámica como una propuesta para abordar el estudio de los cambios en los conjuntos cerámicos. La premisa de esta teoría es que los atributos observables en la cerámica perteneciente a un periodo y región específicos son el resultado de la persistencia diferencial del conocimiento alfarero.

Neff (1992:143) menciona que las sociedades de cualquier época y lugar poseen los conocimientos básicos sobre la elaboración de cerámica. Estos se adquieren a través de la invención, errores en la interpretación de la información y por la creatividad e innovación accidental. Si bien estos conocimientos son compartidos por los alfareros, es posible observar ligeras variaciones individuales en la cerámica. Al ser transmitida de forma inter o intrageneracional, la información sobre la fabricación de cerámica tiende a perderse, reconfigurarse o persistir, aunque esa es una respuesta adaptativa ante presiones selectivas de origen ambiental, social, económico, entre otras. El mecanismo que determina la transmisión de tales conocimientos es la selección natural (Neff, 1992; VanPool, 2001). En otros casos, la información aparece o desaparece en función de procesos aleatorios (Neff, 1992).

Para la identificación de cambios y continuidades es necesario considerar dos unidades de análisis: los atributos estilísticos y los funcionales. Los primeros se 
distinguen por ser adaptativamente neutrales; los segundos, por poseer valores selectivos. De acuerdo con VanPool (2001), los atributos estilísticos presentan una mayor variación en el tiempo-espacio; los funcionales, por el contrario, exhiben una variabilidad más restringida. Esto se debe principalmente a que la selección natural y la transmisión aleatoria generan patrones de variación y conducta distintos. Por otra parte, Vaughan (2001) puntualiza que un mismo rasgo puede ser neutral en un contexto y estar bajo control selectivo en otro.

Los planteamientos de la Arqueología evolutiva y la teoría de la evolución cerámica han sido aplicados por diversos investigadores, a saber, Braun, Neff y Lipo. En primer lugar, Braun (en O’Brien et al., 1994) subraya la persistencia de las paredes gruesas en los conjuntos cerámicos del occidente de Illinois durante la transición del periodo Woodland medio. En segundo lugar, Neff (1992) analiza la aparición de nuevos motivos decorativos en la cerámica Plomiza durante el Posclásico Temprano. Por último, Lipo, Feathers y Dunnell (2005) explican el cambio de desgrasante en los complejos cerámicos del valle del río Mississippi entre el 600 y 900 d.C.

\section{Metodología}

El análisis de los conjuntos cerámicos empleados en la producción de sal se realizó en cuatro etapas. La primera consistió en la clasificación de una muestra de 411 tiestos cerámicos. Se empleó el sistema Tipo-Variedad (Colton, 1953; Wheat, Gifford y Wasley, 1958; Phillip, 1958; Sabloff y Smith, 1969). Los tipos cerámicos se establecieron con base en los criterios: tratamiento de superficie, desgrasante y grosor de la pared. Para la clasificación de este último rasgo se emplearon las categorías utilizadas por Voorhies y Gasco (2004) en el análisis de la cerámica Posclásica de Acapetahua, en la región del Soconusco. Dichas categorías son:
a) Delgado (menor a $3 \mathrm{~mm}$ )
b) Medio (entre 3 y $8 \mathrm{~mm}$ )
c) Grueso (entre 8 y 12)
d) Muy grueso (mayor a $12 \mathrm{~mm}$ )

Las variedades, por otro lado, fueron establecidas a partir del tipo de decoración y la presencia de ligeras variaciones en el tratamiento de superficie.

La segunda etapa del análisis consistió en la identificación y descripción de las formas cerámicas. Se utilizó un esquema de clasificación basado en la proporción de la altura y el diámetro máximo de las vasijas (Rice, 1987), que consta de cinco categorías: 
1. Plato plano: presenta una altura menor a $1 / 5$ de su diámetro máximo.

2. Plato hondo: posee una altura entre $1 / 5$ y $1 / 3$ de su diámetro máximo.

3. Cuenco: su altura es mayor a 1/3 del diámetro máximo o igual al mismo.

4. Vaso: presentan una altura mayor a su diámetro.

5. Jarra: su altura es mayor a su diámetro. Dentro de esta categoría se encuentran las ollas, consideradas un tipo de jarra con orificio restricto (Orton et al., en Navarro, 2014). Para los fines de esta investigación se optó por emplear el término olla en sustitución de jarra, dadas las características que presentan las vasijas de la colección cerámica. Además de esas formas, se incluyó la categoría de tecomate, propuesta y descrita por Sabloff (en Navarro, 2014) porque estas vasijas se localizan con frecuencia en el Soconusco, desde el Preclásico hasta el Posclásico.

6. Tecomates: cuencos con forma similar a la de una calabaza, de orificio restricto.

Con el fin de determinar su cronología, en la tercera etapa del análisis se efectuó una comparación estilística y formal entre los tipos cerámicos identificados y las tipologías de diversos sitios del Soconusco. Las tipologías revisadas fueron la secuencia cerámica de los sitios Preclásicos de la zona de manglar del Soconusco realizada por Paul Burger (2015) y la clasificación cerámica del sitio Clásico Miguel Alemán propuesta por Marx Navarro Castillo (2014), así como la descripción de las vasijas Posclásicas de Acapetahua elaborada por Barbara Voorhies y Janine Gasco (2004). Además de la comparación tipológica, la ubicación temporal de los conjuntos cerámicos se estableció con base en muestras de carbón, recuperadas y fechadas mediante C14 por el Proyecto Arqueológico Costa del Soconusco, en 2012.

La última etapa consistió en la identificación de los atributos estilísticos y funcionales. Si bien VanPool (2001:127) hace énfasis en que la arqueología evolutiva y, en consecuencia, la teoría de la evolución cerámica carecen de una metodología general para la distinción de estos atributos, es preciso señalar que diversos investigadores desarrollaron y aplicaron una amplia variedad de métodos estadísticos paramétricos y no paramétricos para dicho fin. Entre ellos, el coeficiente de variación corregido (CCV), el examen de chi-cuadrado, el análisis de varianza (ANOVA) y la comparación directa (Vaughan, 2001; Pfeffer, 2001). Además de la aplicación de estos métodos, VanPool (2001:123) advierte la importancia de examinar el contexto arqueológico de los artefactos.

\section{8}

Revista Pueblos y fronteras digital • volumen $16 \bullet 2021$, pp. 1-26・ISSN 1870-4115 
En la presente investigación se empleó el método de comparación directa de frecuencias para identificar los atributos estilísticos y funcionales (porque la mayoría de los rasgos analizados son cualitativos y no poseen valores métricos). De acuerdo con O'Brien y Holland (1996: 190,191), la frecuencia de los rasgos que se encuentran bajo el control de la selección natural tiende a aumentar, esto con respecto a las demás variedades. Por el contrario, la frecuencia de los rasgos que no están determinados por este mecanismo tiende a fluctuar, presentándose lapsos de mayor, menor o igual ocurrencia. A partir de estos planteamientos, clasificamos como funcionales los atributos que presentaron una variedad restringida de alternativas, así como notables diferencias en sus frecuencias, y como estilísticos aquellos que exhibieron una mayor variación y frecuencias uniformes.

Igualmente consideramos la asociación que las vasijas tienen con una actividad específica: la producción de sal. Misma que requiere el uso de cerámica con características particulares. La aplicación de esta metodología permitió observar la variabilidad de los atributos, la frecuencia de cada variable y su comportamiento (cambios y continuidades) en dos periodos de producción discontinuos.

\section{Resultados}

El sistema Tipo-Variedad permitió el establecimiento de cinco tipos cerámicos: Café burdo, Rojo burdo, Rojo medio, Rojo fino y Gallo encantado con impresión textil (véanse Figuras 4, 5, 6, 7,8) cada uno con sus respectivas variedades.

Figura 4. Tipo cerámico Café burdo

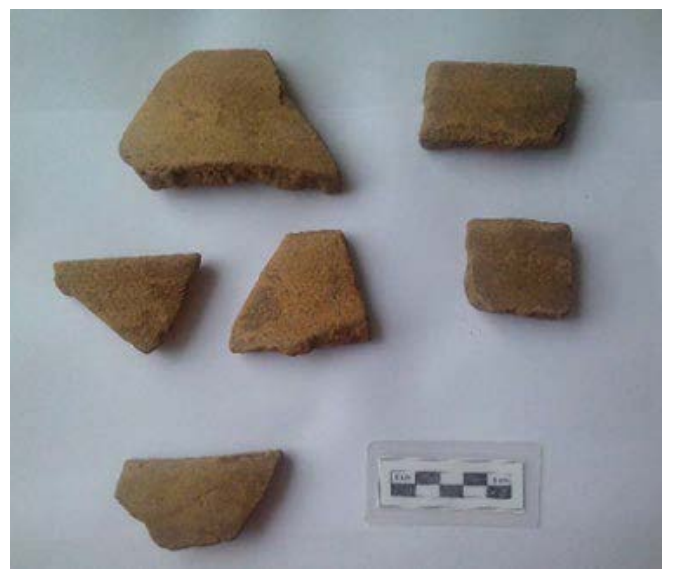

Figura 5. Tipo cerámico Rojo burdo

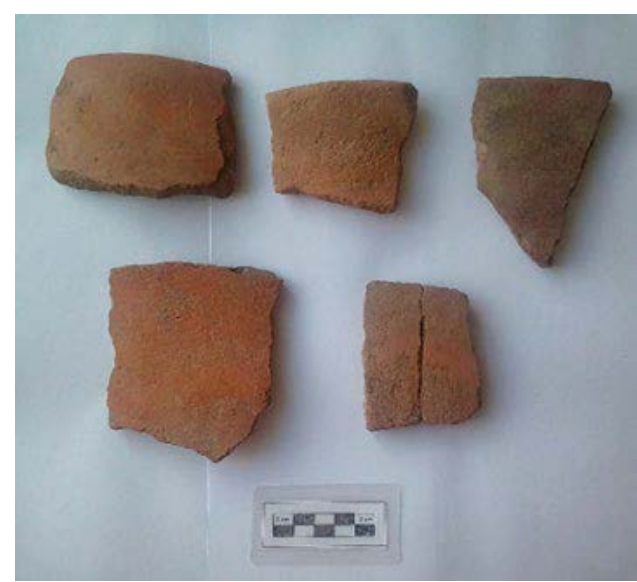

Fuente: Fotografías: Brenda Guadalupe Jiménez Vázquez. 
Figura 6. Tipo cerámico Rojo medio

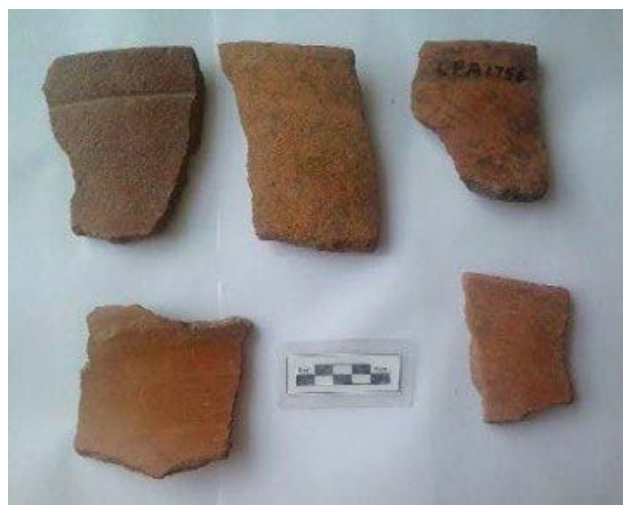

Figura 7. Tipo cerámico Rojo fino

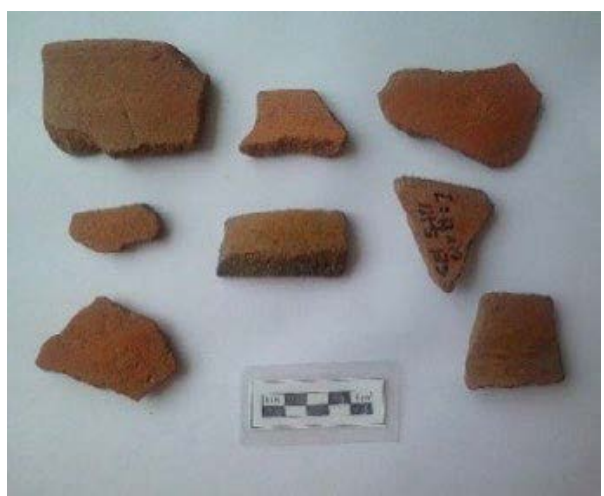

Figura 8. Tipo cerámico Gallo encantado con impresión textil

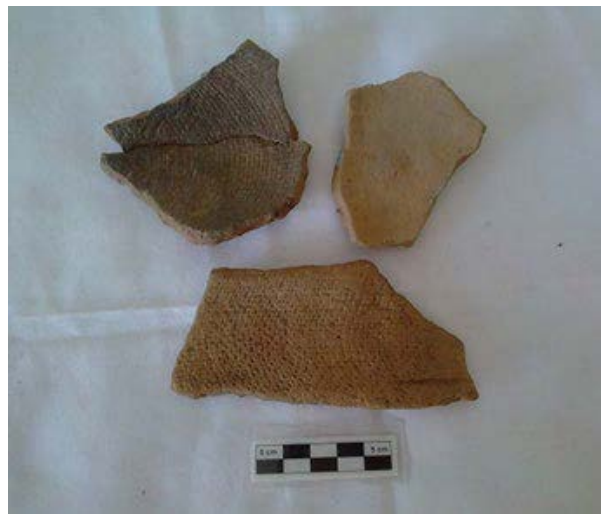

Fuente: Fotografías: Brenda Guadalupe Jiménez Vázquez.

Dadas sus similitudes estilísticas y formales, los tipos Café burdo y Rojo (burdo, medio y fino) fueron clasificados como parte del Complejo Bermúdez, descrito por Paul Burger (2015: 81-101) y fechado para el Preclásico Tardío, entre 400 y 1 a. C. (véase Figura 9).

Figura 9. Resultados de las pruebas de C14 del sitio BER19

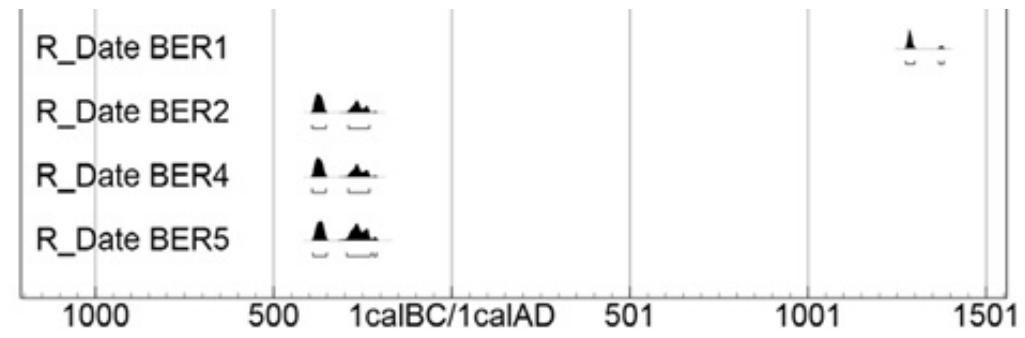

Fuente: tomado de Burger (2015: 17). 
Gallo encantado con impresión textil representa un caso diferente. Su cronología fue establecida mediante una prueba de C14; arrojó una fecha ubicada dentro de los límites temporales del Posclásico Tardío. Es decir, entre 1400 y 1450 d. C. (véase Figura 10).

Figura 10. Resultado de la prueba de C14 del sitio GE1

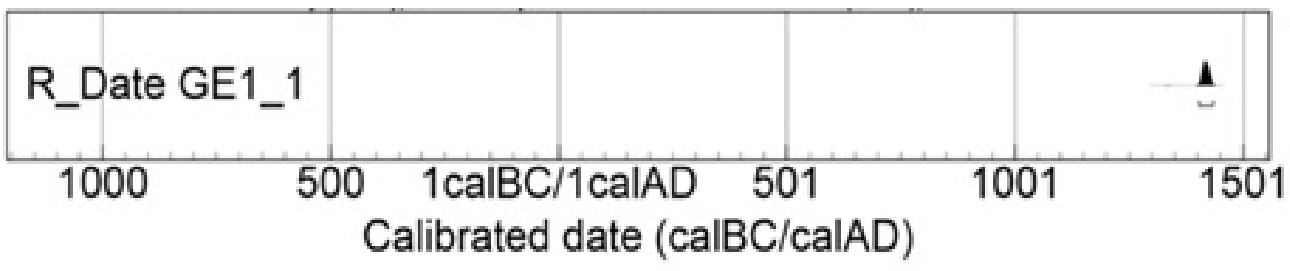

Fuente: tomado de Neff (2012: 11).

Los tipos cerámicos del Preclásico y Posclásico Tardío presentan una amplia variedad de atributos. No obstante, los de interés para esta investigación se limitan al tratamiento de superficie, decoración, grosor de la pared y forma de la vasija. Así pues, el primer atributo que se analizó fue la decoración. Para el Preclásico Tardío presentó un total de tres variedades de contraste. La cerámica del Posclásico Tardío no exhibió atributos decorativos; sin embargo, se observó la presencia de impresiones de textiles en la superficie interior de las vasijas (véase Tabla 1).

Tabla 1. Frecuencia de variedades decorativas e impresión textil

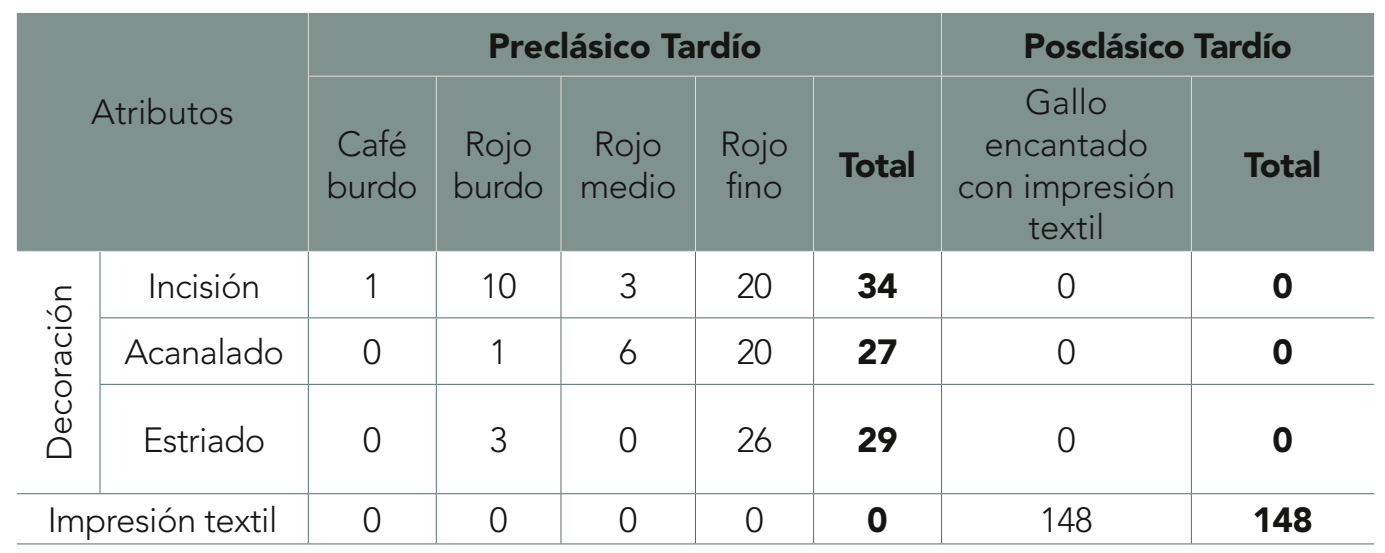

Fuente: elaboración propia. 
Las variedades decorativas identificadas en la cerámica del Preclásico Tardío muestran frecuencias con poca variación (véase Figura 11). Esto indica que no existían preferencias por un tipo de decoración. Por lo tanto, es probable que la trasmisión de dichas variedades se encuentre determinada por mecanismos distintos al de selección natural. Aunado a ello, es preciso señalar que la decoración parece no ser un atributo útil para la cerámica salinera. Los estudios arqueológicos y etnoarqueológicos no consideran la decoración como un atributo importante para el uso/función de las vasijas (Liot, 1995; Santley, 2004; Murata, 2011; Williams, 2016). En resumen, la decoración puede ser clasificada como un atributo estilístico.

El conjunto cerámico del Posclásico Tardío presenta una situación distinta: carece de decoración. La impresión textil es el único atributo observable en la superficie interior de casi todos los ejemplares, con excepción de dos. La alta frecuencia de impresión textil y la ausencia de variedades decorativas sugieren la posibilidad de que este haya sido un rasgo útil, o bien el resultado del uso de una técnica particular en la elaboración de la cerámica. Dado que en ambas posibilidades se observa la intervención del mecanismo de selección natural, la impresión textil deber ser considerada un atributo funcional.

Figura 11. Gráfica de frecuencia de variedades decorativas

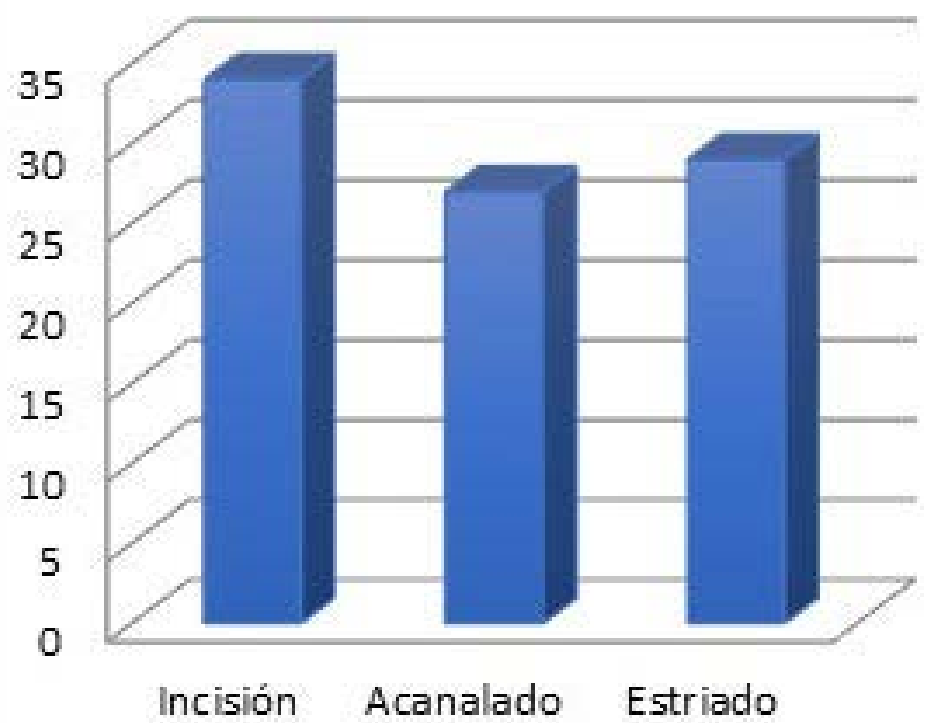

Fuente: elaboración propia. 
El tratamiento de superficie constituyó el segundo atributo bajo análisis en esta investigación. En dicho atributo se observó un total de tres variedades (véase Tabla 2).

Tabla 2. Frecuencia de tratamientos de superficie

\begin{tabular}{l|c|c|c|c|c|c|c|c} 
& \multicolumn{4}{c}{ Preclásico Tardío } & \multicolumn{3}{c}{ Posclásico Tardío } \\
$\begin{array}{l}\text { Tratamiento de } \\
\text { superficie }\end{array}$ & $\begin{array}{c}\text { Café } \\
\text { burdo }\end{array}$ & $\begin{array}{c}\text { Rojo } \\
\text { burdo }\end{array}$ & $\begin{array}{c}\text { Rojo } \\
\text { medio }\end{array}$ & $\begin{array}{c}\text { Rojo } \\
\text { fino }\end{array}$ & Total & $\begin{array}{c}\text { Gallo encantado } \\
\text { con impresión } \\
\text { textil }\end{array}$ & Total \\
\hline Engobe exterior & 10 & 32 & 17 & 172 & $\mathbf{2 3 1}$ & 0 & $\mathbf{0}$ \\
\hline Engobe pulido & 0 & 0 & 1 & 12 & $\mathbf{1 3}$ & 0 & $\mathbf{0}$ \\
\hline Sin tratamiento & 0 & 0 & 0 & 0 & $\mathbf{0}$ & 150 & $\mathbf{1 5 0}$ \\
\hline
\end{tabular}

Fuente: elaboración propia.

Como puede observarse en la Tabla 2, los conjuntos cerámicos del Preclásico Tardío, pertenecientes al Complejo Bermúdez, exhiben una variabilidad restringida en el tratamiento de superficie, que se reduce a solo dos variedades. Ambas muestran claras diferencias en cuanto a su frecuencia, predominando las vasijas con solo engobe exterior. En el caso de la cerámica del Posclásico Tardío, la variabilidad está claramente ausente, pues todos los tiestos de la colección carecen de tratamiento. La distribución y frecuencia del tratamiento de superficie exhiben el predominio de una sola variedad en ambos periodos (véase Figura 12). La presencia de este patrón nos permite sugerir que se trata de un rasgo funcional.

Figura 12. Gráfica de frecuencias de tratamiento de superficie

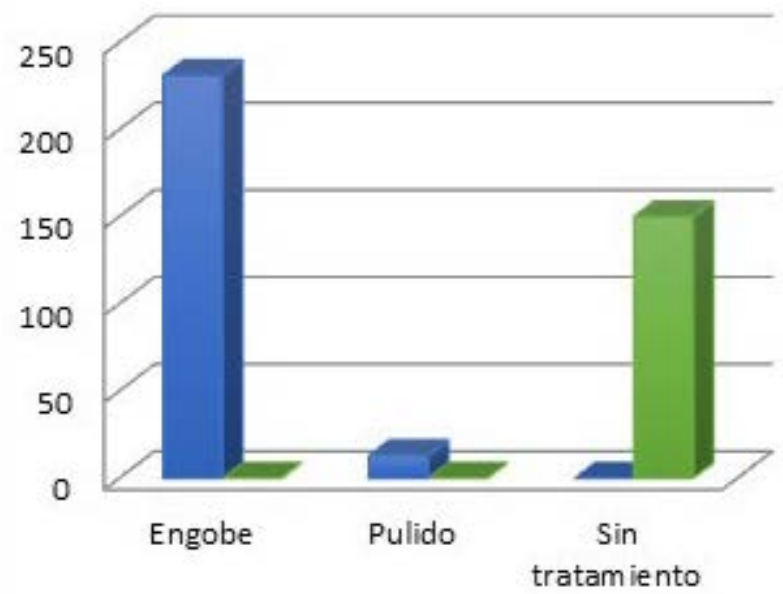

Preclásico Tardío

Posclásico Tardio

Fuente: elaboración propia. 
El tercer atributo bajo análisis fue el grosor de la pared y presentó cuatro variedades en total (véase Tabla 3).

Tabla 3. Frecuencias del grosor de la pared por tipo cerámico y periodo

\begin{tabular}{l|c|c|c|c|c|c|c|c|}
\hline & \multicolumn{4}{|c|}{ Preclásico Tardío } & \multicolumn{2}{c}{ Posclásico Tardío } \\
$\begin{array}{l}\text { Grosor de la } \\
\text { pared }\end{array}$ & $\begin{array}{c}\text { Café } \\
\text { burdo }\end{array}$ & $\begin{array}{c}\text { Rojo } \\
\text { burdo }\end{array}$ & $\begin{array}{c}\text { Rojo } \\
\text { medio }\end{array}$ & $\begin{array}{c}\text { Rojo } \\
\text { fino }\end{array}$ & Total & $\begin{array}{c}\text { Gallo encantado } \\
\text { con impresión } \\
\text { textil }\end{array}$ & Total \\
\hline Delgado & 0 & 0 & 0 & 1 & $\mathbf{1}$ & 9 & $\mathbf{9}$ \\
\hline Medio & 2 & 2 & 4 & 147 & $\mathbf{1 5 5}$ & 132 & $\mathbf{1 3 2}$ \\
\hline Grueso & 9 & 30 & 11 & 46 & $\mathbf{9 6}$ & 9 & $\mathbf{9}$ \\
\hline Muy grueso & 0 & 3 & 3 & 3 & $\mathbf{9}$ & 0 & $\mathbf{0}$ \\
\hline
\end{tabular}

Fuente: elaboración propia.

Los conjuntos cerámicos del Preclásico Tardío presentan variabilidad en cuanto al grosor de sus paredes. La frecuencia de cada variable difiere notablemente del resto, y se observa un mayor predominio de las paredes de tamaño medio, seguidas de las gruesas. En el Posclásico Tardío la variabilidad se ve reducida: desaparecen las paredes muy gruesas. No obstante, las de tamaño medio continúan siendo predominantes (véase Figura 13).

Figura 13. Gráfica de frecuencias del grosor de la pared

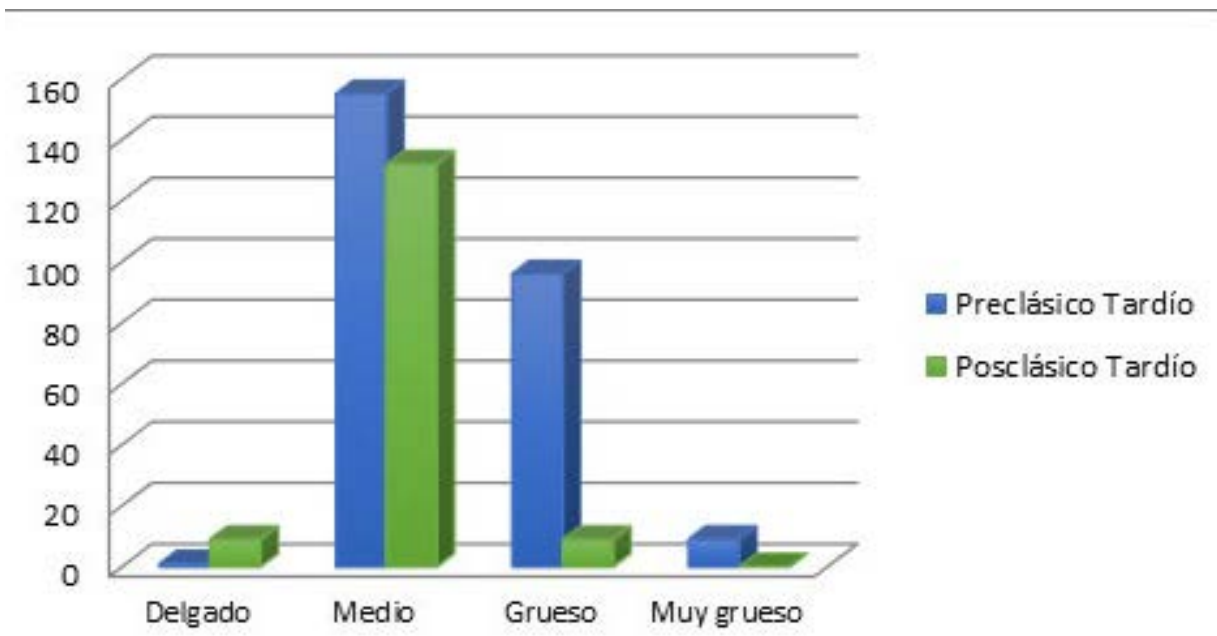

Fuente: elaboración propia. 
El comportamiento de las paredes indica que en ambos periodos existe cierta inclinación por una sola variedad. La presencia de este patrón permite situar dicho atributo dentro de la categoría de funcionales.

Finalmente, el último atributo analizado fue la forma de la vasija. La cantidad total de variedades identificadas en este atributo es de tres (véase Tabla 4).

Tabla 4. Frecuencias de la forma de vasijas por tipo cerámico y periodo

\begin{tabular}{|c|c|c|c|c|c|c|c|}
\hline \multirow[b]{2}{*}{$\begin{array}{c}\text { Forma de } \\
\text { vasija }\end{array}$} & \multicolumn{5}{|c|}{ Preclásico Tardío } & \multicolumn{2}{|c|}{ Posclásico Tardío } \\
\hline & $\begin{array}{l}\text { Café } \\
\text { burdo }\end{array}$ & $\begin{array}{l}\text { Rojo } \\
\text { burdo }\end{array}$ & $\begin{array}{l}\text { Rojo } \\
\text { medio }\end{array}$ & $\begin{array}{l}\text { Rojo } \\
\text { fino }\end{array}$ & Total & $\begin{array}{l}\text { Gallo } \\
\text { encantado con } \\
\text { impresión textil }\end{array}$ & Total \\
\hline Plato hondo & 0 & 0 & 0 & 1 & 1 & 0 & 0 \\
\hline Tecomate & 1 & 1 & 0 & 0 & 2 & 0 & 0 \\
\hline Olla & 9 & 25 & 11 & 56 & 101 & 0 & 0 \\
\hline
\end{tabular}

Fuente: elaboración propia.

La Tabla 4 exhibe una marcada diferencia entre las frecuencias de las tres variedades. La vasta cantidad de ollas contrasta con los pocos ejemplares de platos y tecomates, hace evidente la preferencia por una forma en particular (véase Figura 14). Este patrón de comportamiento selectivo permite clasificar la forma de la vasija como un atributo funcional. Con respecto al conjunto cerámico del Posclásico Tardío, no hubo formas identificables, ya que solamente se localizaron «posibles bordes» en toda la colección.

Figura 14. Gráfica de frecuencia de las formas de las vasijas

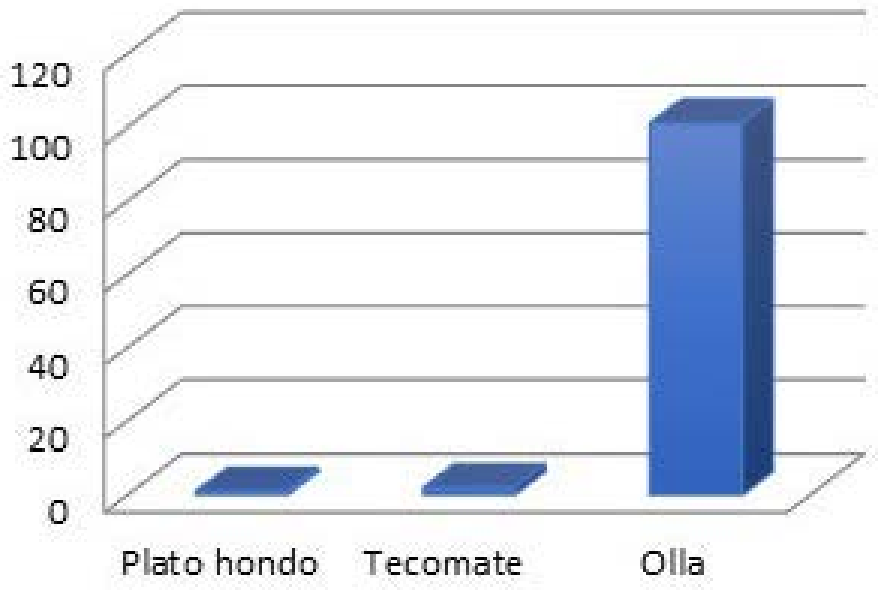

Fuente: elaboración propia. 


\section{Discusión}

El método de comparación directa de frecuencias permitió identificar un atributo estilístico (decoración) y tres funcionales (tratamiento de superficie, grosor de la pared y forma de la vasija) en la cerámica del Preclásico Tardío. También una marcada ausencia de rasgos estilísticos y solamente tres atributos funcionales (impresión textil, tratamiento de superficie y grosor de la pared) en el conjunto del Posclásico Tardío (véase Tabla 5).

Tabla 5. Atributos estilísticos y funcionales del Preclásico y Posclásico Tardío

\begin{tabular}{l|l|l}
\hline Atributos & Preclásico Tardío & Posclásico Tardío \\
\hline Estilísticos & Decoración & \\
\hline \multirow{2}{*}{ Funcionales } & Tratamiento de superficie & Tratamiento de superficie \\
\hline & Grosor de la pared & Grosor de la pared \\
\hline & Forma de la vasija & Impresión textil \\
\hline
\end{tabular}

Fuente: elaboración propia.

Los conjuntos cerámicos empleados en la producción de sal durante el Preclásico Tardío en GE1 pertenecen al Complejo Bermúdez. De igual forma, la cerámica de BER19, otro montículo del mismo periodo asociado con la actividad salinera (Neff, 2012; Neff et al., 2018). En ambos sitios, la cerámica presenta una decoración similar; aunque esta, como se mencionó, no contribuye y tampoco afecta la función de las vasijas. La neutralidad de este rasgo también se observa en otras salinas de Mesoamérica y en el occidente de México, donde se ha documentado el uso de cerámica con y sin decoración (Sisson, 1973; McKillop, 1995; Liot, 1995; Santley, 2004; Murata, 2011; Williams, 2016, 2020). Si bien el comportamiento de este atributo no está determinado por presiones selectivas, su presencia es un indicador de la buena elaboración de las vasijas utilizadas para producir sal durante este periodo en la región del Soconusco.

Las vasijas de GE1 y BER19 también presentan similitudes en el tratamiento de superficie. En ambas es posible observar la presencia de engobe y pulido exterior. Al igual que en otras salinas, el predominio de un solo tratamiento de superficie, en este caso el engobe exterior, se encuentra vinculado con el uso/ función de la cerámica. Sisson (1973) y Neely et al. (1997) mencionan la presencia de recipientes cerámicos con engobe y bruñido interior en el valle de Tehuacán. 
De acuerdo con dichos autores, estos rasgos fueron de gran utilidad, ya que impidieron la filtración de la solución salina. En los conjuntos cerámicos de GE1 el engobe pudo cumplir una función similar: impermeabilizar la superficie de las vasijas para evitar la pérdida de salmuera durante el proceso de cocción. Contrario a esto, algunos investigadores sugieren que las superficies rugosas y porosas (sin tratamiento) fueron más eficientes porque facilitaron la liberación de humedad (Liot, 1995: 28). Sin embargo, Sisson (1973: 92) señala que las vasijas altamente porosas no son útiles para la cocción, por lo que estas probablemente fueron empleadas en el secado de la sal.

En lo que respecta al grosor de las paredes, observamos la presencia de cuatro tipos: delgado, medio, grueso y muy grueso. Solamente el segundo y tercer tipos aparecen con mayor frecuencia. La importancia de este atributo ha sido señalada por Nance (1994: 80), pues sugiere que las paredes delgadas de las ollas localizadas en el Montículo Guzmán facilitaron la extracción de sal mediante la fractura de la vasija, una vez concluido el proceso de extracción, razón por la cual fueron de un solo uso. En contraste, Liot (1995: 26) argumenta que las vasijas de paredes delgadas, por su fragilidad, no son aptas para el transporte de salmuera o sal cocida. Asimismo, O’Brien et al. (1994) señalan que las paredes gruesas parecen ser más efectivas para la cocción cerámica, ya que estas tienden a resistir más la tensión por calor y, por lo tanto, pueden ser utilizadas más de una vez.

Las paredes de los conjuntos cerámicos del Preclásico Tardío son, en su mayoría, de tamaño medio y grueso, miden entre 5 y $11 \mathrm{~mm}$. Esto nos permite sugerir que la alta frecuencia de este rasgo se relaciona con atributos de resistencia y durabilidad. Al poseer la cerámica mayor resistencia, más prolongado sería su uso como recipiente para la cocción o el transporte de salmuera, llegándose a emplear por varios ciclos de producción.

Con referencia a la forma de las vasijas, la más abundante durante este periodo fue la olla. Su presencia en las salinas ha sido ampliamente documentada. Su uso se asocia principalmente con la cocción y, en menor medida, el almacenamiento de salmuera y el transporte de agua (Liot, 1995; Santley, 2004; Murata, 2011). En el caso de GE1, aunque la mayoría de las ollas carecen de manchas negras que indiquen contacto con el fuego, este no parece ser un caso aislado. Liot (1995:27) documentó una situación similar en la cerámica salinera de la cuenca de Sayula. De acuerdo con dicha autora, la ausencia de residuos de carbón en la superficie de las vasijas podría deberse a que estas no mantenían contacto directo con el fuego, sino que eran expuestas a un calor bajo y progresivo. Otra alternativa es que fueran colocadas sobre soportes. 
Neff et al. (2018:403) asocian la cerámica del Complejo Bermúdez, localizada en CONQ18 área 2, CONQ22, PIN7 y BER19, en la zona de esteros y manglares del Soconusco, con actividades pirotecnológicas, entre ellas la producción de sal. Por lo tanto, resulta probable que las ollas de este mismo complejo encontradas en GE1 fueran utilizadas para actividades como la cocción de sal a fuego de baja intensidad.

\section{Posclásico Tardío}

En este periodo observamos un cambio muy significativo en la cerámica salinera de GE1, ya que, a diferencia del anterior, en el Posclásico Tardío la decoración está totalmente ausente. El único rasgo apreciable en la superficie interior de las vasijas es la impresión textil interior, que también ha sido identificada en la cerámica de otros sitios Posclásicos ubicados en el Soconusco, entre ellos Acapetahua, Las Morenas (Voorhies y Gasco, 2004) y Gonzalo Hernández (Gasco, 2015). Sin embargo, estas vasijas no están asociadas con la producción de sal sino con actividades domésticas. Asimismo, fuera de la región del Soconusco se ha localizado cerámica salinera Clásica y Posclásica con impresión textil. Sisson (1973), Neely et al. (1997) y Castellón (2018) reportan la presencia de tiestos con impresión textil en el valle de Tehuacán, en Puebla. Charlton (1969) y Parsons (2015) , por su parte, informan de la existencia de abundantes concentraciones de un tipo cerámico con este rasgo en su superficie exterior, denominado Texcoco con impresión textil, en las salinas de la cuenca de México. En ambas regiones la cerámica presenta un alto grado de especialización y parece haber sido empleada en el secado o empaquetado de la sal (Parsons, 2015: 368).

Pese a que la impresión textil ha sido un tema abordado por diversos investigadores, estos aún no logran explicar la utilidad de este rasgo en las vasijas salineras. Para el caso de GE1, podemos sugerir que su presencia es el resultado de la selección de conocimientos y técnicas de manufactura cerámica. Sin embargo, este supuesto lleva a plantearnos una interrogante clave: ¿cómo se producían las vasijas con impresiones de textil en el interior?

Morris (2004) analizó las vasijas con impresión textil de Acapetahua y realizó una investigación etnográfica sobre las técnicas de producción de comales en localidades de Chiapas. El investigador sugiere que la presencia de este rasgo es el resultado de la aplicación de una técnica de manufactura en la cual se emplean telas para cubrir los moldes usados en la elaboración de vasijas, o bien para prote- 
ger la superficie sobre la cual se efectúa el modelado. Esta técnica se utilizó para producir vasijas de uso doméstico y quizá también para elaborar cerámica destinada a otras actividades. Brown (1980: 30-34) menciona el uso de un procedimiento parecido en la elaboración de las cazuelas de sal misisipianas con impresiones de textil. Atendiendo a estos ejemplos podemos sugerir un proceso de manufactura similar para las vasijas de GE1. Con todo, hasta el momento no existen suficientes pruebas para corroborar tal supuesto.

Otro rasgo distintivo de la cerámica de este periodo es la ausencia de tratamiento y las superficies burdas e irregulares. Estas características fueron identificadas en la cerámica Texcoco con impresión textil (Charlton, 1969; Parsons, 2015) y en los tiestos del valle de Tehuacán (Neely et al, 1997). De acuerdo con Nance (1992: 80), las vasijas que carecen de tratamiento superficial se utilizaron en la cocción de salmuera. Aunque en el caso de la cerámica con impresión textil del valle de Tehuacán y la cuenca de México se encuentra más asociada con el secado y empaquetado de sal (Sisson, 1973; Parsons, 2015), pues su alta porosidad favorece la pérdida de humedad. Dadas sus similitudes con esta cerámica, es probable que Gallo encantado con impresión textil tuviera un uso parecido. En cuanto al grosor de las paredes, exhibe un patrón de comportamiento similar al del Preclásico Tardío, ya que las paredes de tamaño medio continúan siendo predominantes. Pese a la abundancia de este tipo de pared, la cerámica con impresión textil pudo ser, por las características de su superficie exterior (burda y áspera) y la poca compactación de la pasta, menos resistente que los conjuntos del periodo anterior.

Con respecto a la forma de las vasijas, no se pudo identificar ninguna, ya que solamente se localizaron «posibles bordes». Ante tal situación persiste la incertidumbre sobre cuál era la forma de la cerámica con impresión textil. Si bien no es factible dar una respuesta concreta a esta interrogante, se pueden hacer algunas inferencias con base en los ejemplares impresos estudiados por Morris y el tipo Texcoco con impresión textil. De acuerdo con Morris (2004:196-197), la técnica de manufactura de las vasijas con impresión textil de Acapetahua no pudo ser aplicada en la elaboración de formas cerradas como las ollas o los tecomates, puesto que para extraer el molde o efectuar el modelado fue necesario que las vasijas tuvieran una boca y paredes abiertas.

En el caso de Texcoco con impresión textil, Parsons (2015: 351) logró identificar cuatro tipos de vasijas abiertas: circular con base plana, cónica, circular con base oval, rectangular y oval. Este autor plantea que la variación formal de la cerámica 
indica la existencia de distintas unidades de medida para el comercio e intercambio de la sal. Tomando como referente estos ejemplos, es posible argumentar que la cerámica de este periodo estuvo compuesta por varios y no por un solo tipo de forma abierta. No obstante, es necesario un minucioso análisis de los tiestos con impresión textil.

\section{Reflexiones finales}

Los conjuntos cerámicos del Complejo Bermúdez, que se utilizaron en la producción de sal durante el Preclásico Tardío en el sitio GE1, exhiben una buena elaboración y calidad. Esto en contraste con lo que se observa en otras salinas de Mesoamérica y del occidente de México, donde se ha documentado la presencia de vasijas con muy poca cocción, burdas y rugosas (Nance, 1992; Liot 1995). Aunque los atributos analizados (decoración, tratamiento de superficie, grosor de la pared, forma de la vasija) presentan más de una variable o alternativa, la mayoría de estos, con excepción de la decoración, muestran patrones de variación selectivos. Esto nos permite aducir que los atributos que aparecen con mayor frecuencia en la cerámica de este periodo, como son los engobes, las paredes de tamaño medio-grueso y las ollas contribuyeron a que las vasijas tuvieran mayor resistencia y fueran más eficientes en su uso para la producción de sal mediante la técnica de sal cocida.

El empleo de recipientes mejor elaborados y más resistentes puede estar relacionado con la intensificación de la producción salina que, de acuerdo con Neff et al. (2018: 405) , ocurrió en el Soconusco durante el Preclásico Tardío, como resultado del incremento demográfico en las poblaciones del interior y el auge de un importante centro: Izapa. La alta demanda de sal pudo actuar como factor de presión selectiva para el desarrollo de una cerámica especializada de uso prolongado, la cual pudiera ser empleada en varios ciclos de producción y no se desechara después de haber sido utilizada por primera vez.

En el Posclásico Tardío observamos cierta continuidad en algunos patrones de comportamiento, pero existe un cambio sustancial, debido a la ausencia de los atributos que distinguen la cerámica del Preclásico Tardío, a excepción del grosor de las paredes, que continúa siendo predominantemente medio. Cabe señalar como aspecto importante que, además de haberse identificado un solo tipo cerámico en este periodo, las vasijas que lo constituyen tienden a ser homogéneas. Esta homogeneidad es, sin duda alguna, el resultado de un proceso 
continuo de selección natural que derivó en la especialización de la cerámica. A diferencia del anterior, las vasijas de este periodo pudieron haber sido fabricadas para ser usadas una sola vez.

La intensificación de las relaciones comerciales y el intercambio a larga distancia probablemente impulsaron el desarrollo de una producción de sal a gran escala en el Soconusco durante el Posclásico Tardío y, en consecuencia, ejercieron una presión selectiva. Es preciso recordar que, al igual que el centro de México, la región del Soconusco participó activamente en las redes de intercambio a larga distancia al importar y exportar diversos productos (Gasco, 2012).

Pese a que los conjuntos cerámicos analizados fueron utilizados en periodos distintos, en ambos es posible observar la presencia de dos formas de especialización, cada una influenciada por el contexto económico y social imperante.

En GE1 se localizó una concentración de tiestos correspondiente al Clásico, aunque no se asocia con la producción salina ni con actividades domésticas. Debido a ello se ha sugerido que en este periodo el sitio fue un punto de exportación de cerámica Plomizo Tohil. El supuesto se apoya en la buena calidad que exhiben los ejemplares recuperados, la ubicación del sitio (a orillas de un antiguo canal) y la falta de evidencia que indique su función habitacional. De acuerdo con Neff (2014: 6) , durante el Clásico el foco de actividades pirotecnológicas se trasladó al norte del río Cahuacán. Esto podría explicar la ausencia de cerámica asociada con la producción de sal en GE1 en este periodo.

La aplicación de los planteamientos de la arqueología evolutiva y la teoría de la evolución cerámica han sido de gran utilidad para identificar cambios y continuidades en los conjuntos cerámicos empleados en la producción de sal, así como para realizar inferencias sobre las posibles presiones selectivas que dieron origen a dichos cambios. En la arqueología es necesaria la implementación de perspectivas que brinden las herramientas teóricas y metodológicas para abordar el estudio de la variabilidad y el cambio en los artefactos.

\section{Agradecimientos}

El autor principal agradece a la Universidad de Tlaxcala y a su rector, el Dr. Luis González Placencia, por las facilidades otorgadas para la publicación de este artículo. 
La producción de sal en el sitio Gallo Encantado (GE1), Chiapas, México:

análisis de la tecnología cerámica desde la arqueología evolutiva

MARX NAVARRO CASTILLO • BRENDA GUADALUPE JIMÉNEZ VÁZQUEZ • HECTOR NEFF

\section{Bibliografía citada}

Andrews, Anthony. (1980). The Salt Trade of the Ancient Maya. Archaeological Institute of America, 33 (4), pp. 24-33, disponible en https://www.jstor.org/stable/41726336 (consulta: 13/12/2020).

Andrews, Anthony. (1991). Las salinas de El Salvador: bosquejo histórico, etnográfico y arqueológico. Mesoamérica. 12(21), pp. 71-94, disponible en https://dialnet.unirioja. es/servlet/articulo?codigo=3731271 (consulta: 18/05/2018).

Barton, C. M. y G.A Clark.(1997). Evolutionary Theory in Archaeological Explanation. En C. M. Barton y G.A. Clark (Eds.), Rediscovering Darwin: Evolutionary Theory in Archaeological Explanation. (pp.3-15). Arlington, Estados Unidos: AP3A.

Berna, Francesco, Adi Behar, Ruth Shahack-Gross, John Berg, Elisabetta Boaretto, Ayelet Gilboa, et al. (2007). Sediment Exposed to High Temperatures: Reconstruing Pyrotechnological Processes in Late Bronze and Iron Age Strata at Tel Dor (Israel). Journal of Archaeological Science, (34), pp. 358-373, doi: 10.1016/j.jas.2006.05.011

Boone, J. L. y E. A. Smith. (1998). Is It Evolution Yet? A Critique of Evolutionary Archaeology. Current Anthropology, 39, pp. S141-S173.

Broughton, Jack y James O'connell. (1999). On Evolutionary Ecology, Seleccionist Archaeology and Behavioral Archaeology. American Antiquity, 64 (1), pp. 153-165, doi: 10.2307/2694351

Brown, I. W. (1980). Salt and the Earstern North American Indian, An Archaeological Study. Cambridge: Harvard University.

Burger, Paul. (2015). A Formative Ceramic Sequence of Coastal Soconusco.Tesis de maestría inédita. Long Beach, California: California State University.

Castellón Huerta, Blas. (2017). Aportaciones recientes en el estudio de las tecnologías salinas tradicionales en México y Centroamérica. De Re Metallica, (28), pp. 85-96, disponible en https://dialnet.unirioja.es/servlet/articulo?codigo=6579612 (consulta: 27/05/2019).

Castellón Huerta, Blas. (2018). Cuando la sal era una joya: Antropología, arqueología y tecnología de la sal durante el Posclásico en Zapotitlán Salinas, Puebla. México: Instituto Nacional de Antropología e Historia.

Charlton, Thomas. (1969). Texcoco Fabric-Marked Pottery, Tlateles, and Salt Making. American Antiquity, 34(1), pp. 73-76, doi: 10.2307/278316

Colton, Harold S. (1953). Potsherds: An Introduction to the Study of Prehistoric Southwestern Ceramics and Their Use in Historical Reconstruction. Flagstaff, Estados Unidos: Northern Arizona Society of Science and Art.

Darwin, Charles. (1877). On the Origin of Species by Means of Natural Selection, or the Preservation of Favoured Races in the Struggle for Life. España: Biblioteca Perojo.

Dunnell, Robert. (1978). Style and Function: A Fundamental Dichotomy. American Antiquity, 43 (2), pp. 192-202, doi: 10.2307/279244

Dunnell, Robert. (1982). Evolutionary Theory and Archaeology. En M. B. Schiffer (Ed.), Advances in Archaeological Method and Theory, (pp. 35-91). Nueva York, Estados Unidos: University of New York, Academic Press. 
Dunnell, Robert. (1996a). Natural Selection, Scale, and Cultural Evolution: Some Preliminary Considerations. En M. O'Brien (Ed.), Evolutionary Archaeology. Theory and Application, (pp. 24-29). Salt Lake: University of Utah Press.

Dunnell, Robert. (1996b). Aspects of the Application of Evolutionary Theory in Archaeology. En M. O'Brien (Ed.), Evolutionary Archaeology. Theory and Application, (pp. 86-97). Salt Lake, Estados Unidos: University of Utah Press.

Gasco, Janine. (2012). El paisaje del Soconusco desde el Posclásico Tardío hasta el siglo XX. En LS. Lowe y M. E. Pye (Eds.), Arqueología Reciente de Chiapas: Contribuciones del Encuentro Celebrado en el $60^{\circ}$ Aniversario de la Fundación Arqueológica Nuevo Mundo, Papers of the New World Archaeological Foundation Núm. 72, (pp. 295312). Chiapas, México: NWAF.

Gasco, Janine. (2015). Investigaciones arqueológicas recientes en Gonzalo Hernández, un sitio del Preclásico Tardío en el Soconusco. Entre diversidades, (4), pp. 13-33, doi: 10.31644/ED.4.2015.a01

Lanata, José Luis, Marcelo Cardillo, Virginia Pineau y Silvana Rosenfeld. (2004). La reacción de la década de 1980 y la diversidad teórica posprocesual. En José Luis Lanata y Ana Margarita Aguirre (Eds.), Explorando algunos temas de Arqueología, (pp. 3582). Buenos Aires, Argentina: Gedisa.

Lipo, Carl P., James K. Feathers y Robert C. Dunnell. (2005). Temporal Data Requirements, Luminescence Dates, and the Resolution of Chronological Structure of Late Prehistoric Deposits in the Central Mississippi River Valley. American Antiquity, 70(3), pp. 527-544, doi: 10.2307/40035312

Liot, Catherine. (1995). Evidencias arqueológicas de producción de sal en la cuenca de Sayula (Jalisco): relación con el medio físico, estudio de tecnología. En J. C. Reyes (Coord.), La sal en México, (pp. 3-32). Colima, México: Universidad de Colima.

McKillop, Heather. (1995). Underwater Archaeology, Salt Production, and Coastal Maya Trade at Stingray Lagoon, Belize. Latin American Antiquity, 6(3), pp. 214-228, doi: $10.2307 / 971673$

McKillop, Heather. (2005). Finds in Belize document Late Classic Maya Salt Making and Canoe Transport. PNAS, 102(15), pp. 5630-5634, doi: 10.1073/pnas.0408486102

Monckeberg, Fernando. (2012). La sal es indispensable para la vida, Pero ¿cuánta? Revista chilena de nutrición, 39(4), pp. 192-195, doi: 10.4067/S0717-75182012000400013

Morris, Walter F. (2004). Apendix A. Textile Impressions on Potsherds from the Proyecto Soconusco Study Area. En Barbara Voorhies y Janine Gasco (Eds.), Postclassic Soconusco Society. The Late Prehistory of the Coast of Chiapas, México, (pp.183198). Nueva York, Estados Unidos: Institute for Mesoamerican Studies, University at Albany.

Murata, Satoru. (2011). Maya Salters, Maya Potters: The Archaeology of Multicrafting on Non-residential Mounds at Wits Cah Ak'al, Belize. Tesis doctoral inédita. Boston, Estados Unidos: Boston University.

Nance, C. Roger. (1992). Guzmán Mound: A Late Preclassic Salt Works on the South Coast of Guatemala. Ancient Mesoamerica, 3, pp. 27- 46, doi: 10.1017/S095653610000 
La producción de sal en el sitio Gallo Encantado (GE1), Chiapas, México:

análisis de la tecnología cerámica desde la arqueología evolutiva

MARX NAVARRO CASTILLO • BRENDA GUADALUPE JIMÉNEZ VÁZQUEZ • HECTOR NEFF

Nance, C. Roger. (1994). El Montículo Guzmán: Un sitio Preclásico Tardío de producción de sal cerca de Tilapa, San Marcos, Guatemala. En J.P. Laporte, H. Escobedo y S. Villagrán (Eds.), Simposio de Investigaciones Arqueológicas en Guatemala. Guatemala: Museo Nacional de Arqueología y Etnología.

Navarro Castillo, Marx. (2014). Households Economies: The Production and Consumption of Plumbate at Miguel Aleman, the Conquista Campesina Complex and the Piñuela Complex. Tesis doctoral inédita, Nueva York: University at Albany/State University of New York.

Navarro Castillo, Marx y Hector Neff. (2020). Identificando áreas de actividad a través del uso de GPR en la costa del Soconusco. Estudios de Cultura Maya, 55, pp. 41-63, doi: 10.19130/iifl.ecm.55.2020.0002

Neely, James A., S. Christopher Caran y Francisca Ramírez-Sorensen. (1997). The Prehispanic and Colonial Saltworks of the Tehuacan Valley and Vecinity, Southern Puebla, Mexico. Presentado en la LXII Annual Meeting Society for American Archaeology, Nashville.

Neff, Hector. (1992). Ceramics and Evolution. Archaeological Method and Theory, 4, pp. $141-193$.

Neff, Hector . (2001). Differential Persistence of What? The Scale of Selection Issue in Evolutionary Archaeology. En T. D. Hurt y G. F. M. Rakita (Eds.), Style and Function. Conceptual Issues in Evolutionary Archaeology, (pp. 25-40). Estados Unidos de América: BERGIN \& GARVEY.

Neff, Hector . (2012). Proyecto Arqueológico Costa del Soconusco (PACS): Informe de la primera temporada de campo y solicitud de permiso para Julio 2014 hasta Junio de 2015. México: Consejo de Arqueología-Instituto Nacional de Antropología e Historia.

Neff, Hector . (2014). Proyecto Arqueológico Costa del Soconusco (PACS): Informe de la segunda temporada de campo y solicitud de permiso una segunda temporada. México: Consejo de Arqueología. Instituto Nacional de Antropología e Historia.

Neff, Hector, Paul H. Burger, Brendan J. Culleton, Douglas J. Kenneth y John G. Jones. (2018). Izapa's Industrial Hinterland: the Eastern Soconusco Mangrove Zone During Archaic and Formative Times. Ancient Mesoamerica, (29), pp. 395-411, doi: 10.1017/ S0956536118000299

O'Brien, Michael J.y Thomas D Holland. (1996). Variation, Selection, and the Archaeological Record. En M. O'Brien(Ed.), Evolutionary Archaeology. Theory and Application, (pp. 177-200). Salt Lake, Estados Unidos: University of Utah Press .

O’Brien, Michael J., Thomas D. Holland, Robert J. Hoard y Gregory L Fox. (1994). Evolutionary Implications of Design and Performance Characteristics of Prehistoric Pottery. Journal of Archaeological Method and Theory, 1(3), pp. 259 - 304, disponible en: https://www.jstor.org/stable/20177313 (consulta: 11/05/2019).

Parsons, Jeffrey R. (2015). Los últimos salineros de Nexquipayac, México. Un estudio de etnografía arqueológica. México: El Colegio Mexiquense.

Pfeffer, Michael T. (2001). Implications of New Studies of Hawaiian Fishook Variability for Our Understanding of Polynesian Settlement History. En T. D. Hurt y G. F. M. Rakita (Eds.), Style and Function. Conceptual Issues in Evolutionary Archaeology, (pp. 119140). Estados Unidos de América: BERGIN \& GARVEY. 
La producción de sal en el sitio Gallo Encantado (GE1), Chiapas, México:

análisis de la tecnología cerámica desde la arqueología evolutiva

MARX NAVARRO CASTILLO • BRENDA GUADALUPE JIMÉNEZ VÁZQUEZ • HECTOR NEFF

Phillips, Philip. (1958). Application of the Wheat-Gifford-Wasley Taxonomy to Eastern Ceramics. American Antiquity, 2(2), pp. 117-125, doi: 10.2307/277473

Preucel, Robert W. (1999). Evolutionary Archaeology: Theory and Application. Review. Journal of Field Archaeology, 26, pp. 93-99, disponible en: https://www.jstor.org/ stable/530628 (consulta: 09/03/2018).

Romero Berny, Emilio I. (2012). Manglares del Soconusco, Chiapas: estructura y cambios a nivel de paisaje. Tesis de maestría inédita. San Cristóbal de Las Casas, Chiapas, México: El Colegio de la Frontera Sur.

Rice, Prudence. (1987). Pottery Analysis: A Sourcebook. Chicago, Estados Unidos: University of Chicago Press.

Rindos, David. (1996). Undirected Variation and the Darwinian Explanation of Cultural Change. En M. O'Brien (Ed.), Evolutionary Archaeology. Theory and Application, (pp.152-176). Salt Lake, Estados Unidos: University of Utah Press .

Rosenswig, Robert. (2019). The Izapa Kingdom`s Capital: Formative Period Settlement Patterns, Population, and Dating Low-Relief Stelae. Latin American Antiquity, 30(1), pp. 91-108, doi: 10.1017/laq.2018.83

Sabloff, Jeremy y Robert E. Smith. (1969). The Importance of both Analytic and Taxonomic Classification in the Type-Variety System. American Antiquity, 34(3), pp. 278-285, doi: $10.2307 / 278410$

Santley, Robert S. (2004). Prehistoric Salt Production at El Salado, Veracruz, Mexico. Latin American Antiquity, 15(2), pp. 119-221, doi: 10.2307/4141554

Sisson, Edward B. (1973). First Annual Report of the Coxcatlán Project. Andover: R.S. Peabody Foundation (Tehuacan Project Reports, núm. 3).

VanPool, Todd L. (2001). Style, Function, and Variation: Identifying the Evolutionary Importance of Traits in the Archaeological Record. En T. D. Hurt y G. F. Rakita (Eds.), Style and Function. Conceptual Issues in Evolutionary Archaeology, (pp. 119-140). Estados Unidos de América: BERGIN \& GARVEY.

Vaughan, David C. (2001). A Million Years of Stile and Function: Regional and Temporal Variation in Acheulean Handaxes. En T. D. Hurt y G. F. M. Rakita (Eds.), Style and Function. Conceptual Issues in Evolutionary Archaeology (pp. 141-164). Estados Unidos de América: BERGIN \& GARVEY.

Voorhies, Bárbara y Janine Gasco. (2004). Postclassic Soconusco Society. The Late Prehistory of the Coast of Chiapas, Mexico. Nueva York, Estados Unidos: Institute for Mesoamerican Studies, University at Albany .

Williams, Eduardo. (2016). La sal de la tierra: etnoarqueología de la producción salinera en el Occidente de México. Michoacán, México: El Colegio de Michoacán, 2a. edición.

Williams, Eduardo. (2020). Salt Production in Mesoamerica: Tool Asemblages and Cultural Lanscapes. (Documento inédito).

Wheat, Ben J., James C. Gifford y William W. Wasley. (1958). Ceramic Variety, Type Cluster, and Ceramics System in Southwestern Pottery Analysis. American Antiquity, 24(1), pp. 34-47, doi: 10.2307/276739

Woodfill, Brent K. S., Brian D. Dillion, Marc Wolf, Carlos Avendaño y Ronald Canter. (2015). Salinas de los Nueve Cerros, Guatemala: A Major Economic Center in 
the Southern Maya Lowlands. Latin American Antiquity, 26(2), pp. 162-179, doi: 10.7183/1045-6635.26.2.162

\section{Cómo citar este artículo:}

Navarro Castillo Marx, Brenda Guadalupe Jiménez Vázquez y Hector Neff (2021), «La producción de sal en el sitio Gallo encantado (GE1), Chiapas, México: análisis de la tecnología cerámica desde la arqueología evolutiva». Revista Pueblos y fronteras digital, 16, pp.1-26, doi: 10.22201/cimsur.18704115e.2021.v16.534 